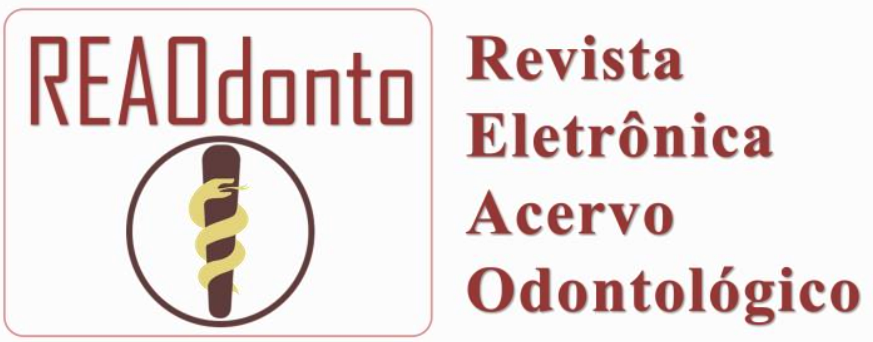

REVISÃO BIBLIOGRÁFICA

Recebido em: 10/2020

Aceito em: $11 / 2020$

Publicado em: 1/2021

\title{
O papel do 10-MDP no processo da adesão
}

\author{
The role of 10-MDP in the adhesion process \\ El papel de 10-MDP en el proceso de adhesión
}

Amanda da Silva Lima ${ }^{1 *}$, Gabriel Ramos Rúbio', Lorena dos Santos Rodrigues¹, Nathalia Silveira Finck ${ }^{1}$.

\begin{abstract}
Resumo: Esse artigo buscou analisar a atuação dos monômeros funcionais no processo da adesão. A introdução destes nos sistemas adesivos permitiu intensificar as forças adesivas através de ligações químicas e, dessa forma, aumentar a qualidade da odontologia restauradora. O 10-metacriloiloxidecil dihidrogênio fosfato (10-MDP) é um monômero que possui a capacidade de melhorar a adesão quando comparado aos outros monômeros funcionais. Dessa forma, o objetivo deste artigo é apresentar, por meio de uma revisão de literatura, o papel do monômero 10-MDP no processo de adesão em restaurações dentárias. Foi realizado um levantamento bibliográfico nas bases de dados Medline, BVS e Lilacs utilizando como termos de busca: Falha de Restauração Dentária; Cimentos Dentários; Odontologia; Adesivos. A literatura enfatiza que o 10-MDP é um monômero que se destaca por apresentar ligação tanto a hidroxiapatita dos tecidos dentais quanto aos compósitos e cimentos resinosos promovendo, assim, uma união mais estável e duradoura. Além disso, também atua como agente ligante entre compósitos resinosos e óxidos metálicos, melhorando a resistência de união à zircônia, por exemplo, através de uma interação química entre sua superfície e o cimento resinoso aplicado. Sendo assim, o 10-MDP é considerado como padrão ouro para adesão em dentina.
\end{abstract}

Palavras-chave: Falha de restauração dentária, Odontologia, Adesivos.

Abstract: This article aims to analyze the role of functional monomers in the adhesion process. The introduction of these in the adhesive systems allowed to intensify the adhesive forces through chemical bonds and, thus, increase the quality of restorative dentistry. 10-Methacryloyloxydecyl dihydrogen phosphate (10-MDP) is a monomer that has the ability to promote better adhesion when compared to other functional monomers. Thus, the objective of this article is to present, through a literature review, the role of monomer $10-\mathrm{MDP}$ in the adhesion process in dental restorations. A bibliographic survey was carried out in the Medline, BVS and Lilacs databases using the following search terms: Dental Restoration Failure; Dental Cements; Dentistry; Adhesives. The literature emphasizes that 10-MDP is a monomer that stands out for having a bond both with hydroxyapatite in dental tissues and with resin composites and cements, thus promoting a stable and lasting bond strength. In addition, it also acts as a bonding agent between resin composites and metal oxides, improving the bond strength to zirconia, for example, through a chemical interaction between its surface and the applied resin cement. Thus, 10-MDP is considered the gold standard for dentin adhesion.

Keywords: Dental restoration failure, Dentistry, Adhesives.

Resumen: Este artículo buscó analizar el papel de los monómeros funcionales en el proceso de adhesión. La introducción de estos en los sistemas adhesivos permitió intensificar las fuerzas adhesivas a través de uniones químicas y, así, aumentar la calidad de la odontología restauradora. El fosfato de dihidrógeno 10metacriloiloxidecilo (10-MDP) es un monómero que tiene la capacidad de mejorar la adhesión en

${ }^{1}$ Centro Universitário Doctum (Unidoctum), Serra - ES. *E-mail: amandalima1704@hotmail.com 
comparación con otros monómeros funcionales. Así, el objetivo de este artículo es presentar, mediante una revisión de la literatura, el papel del monómero 10-MDP en el proceso de adhesión en las restauraciones dentales. Se realizó un relevamiento bibliográfico en las bases de datos Medline, VHL y Lilacs utilizando los siguientes términos de búsqueda: Dental Restoration Failure; Cementos dentales; Odontología; Adhesivos. La literatura enfatiza que el 10-MDP es un monómero que destaca por tener una conexión tanto con la hidroxiapatita de los tejidos dentales como con los composites y cementos resinosos, promoviendo así una unión más estable y duradera. Además, también actúa como un agente de unión entre los compuestos de resina y los óxidos metálicos, mejorando la fuerza de unión a la zirconia, por ejemplo, a través de una interacción química entre su superficie y el cemento de resina aplicado. Por tanto, el 10-MDP se considera el estándar de oro para la adhesión a la dentina.

Palabras clave: Fracaso de la Restauración Dental, Odontología, Adhesivos.

\section{INTRODUÇÃO}

Por muitos anos a principal falha na Odontologia restauradora foi a adesão do material resinoso ao substrato dental. Essa deficiência acarretava, principalmente, em infiltração marginal e cárie secundária, fatores estes que reduziam o sucesso da restauração. Em 1955, Buonocore ao analisar que nas indústrias o tratamento de superfícies metálicas com ácido fosfórico auxiliava na aderência das tintas, introduziu, de forma análoga na Odontologia, a técnica do condicionamento ácido em esmalte, revolucionando assim a Odontologia adesiva. Esse método baseia-se no processo de desmineralização e criação de microrretenções na superfície dental, o que torna desnecessário preparos cavitários extensos e, ainda, amplia expressivamente a qualidade da adesão em restaurações dentárias (CARVALHO EC, et al., 2019).

Nesse contexto, existe a adesão mecânica e a adesão química. A adesão mecânica ocorre a partir do condicionamento com ácido fosfórico e, consequente, formação de microporosidades que possibilitam a penetração dos monômeros resinosos na superfície dental por capilaridade e, dessa forma, obtém-se a união dos substratos por embricamento mecânico. Já a adesão química é observada em dentina e ocorre através de ligações químicas entre monômeros funcionais, como por exemplo, o 10-metacriloiloxidecil dihidrogênio fosfato (10-MDP) e a estrutura dentária (CARVALHO EC et al., 2019; MEERBEEK BV, et al., 2020; CARDOSO MV, et al., 2011).

Estes monômeros se diferenciam por possuírem o grupo fosfato, que se liga ao cálcio (presente na estrutura do esmalte e da dentina), e o grupo metacrilato, que se adere à resina e ao cimento resinoso, promovendo uma ligação mais duradoura e estável (CARRILHO E, et al., 2019; FEITOSA VP, et al.,2014)

Apesar das melhorias alcançadas ao longo dos anos, a união adesiva ainda apresenta alguns impasses como degradação hidrolítica, contração de polimerização e permeabilidade. Por tais motivos, os monômeros funcionais foram introduzidos nos sistemas adesivos com intuito de intensificar as forças adesivas através de ligações químicas e, dessa forma, aumentar a qualidade da Odontologia restauradora tornando-a mais efetiva e satisfatória.

Materiais que apresentam estes monômeros funcionais são Clearfil SE Bond, adesivo autocondicionante com indicação para restaurações diretas, Single Bond Universal, adesivo universal com diferencial de possibilitar ao operador escolher que tipo de técnica mais se adequa (técnica de condicionamento total, seletivo em esmalte ou autocondicionante) indicado para restaurações adesivas ou tratamento prévio à cimentos resinosos, All-Bond Universal, sistema adesivo universal com indicação para restaurações tanto diretas quanto indiretas, Ambar, adesivo convencional de dois passos, utilizado para restaurações diretas ou indiretas combinado com cimento resinoso, Clearfil Ceramic Primer, primer cerâmico com indicação de silanização de cerâmicas vítreas e tratamento de superfície de peças metálicas em cerâmicas cristalinas, RelyX Ultimate, cimento resinoso convencional indicado para cerâmicas vítreas e cristalinas, Panavia F 2.0 Half, cimento resinoso dual autocondicionante com liberação de flúor indicado para cimentação protética, Alloy Primer, primer para metal com indicação para tratamentos de superfície de cerâmicas cristalinas. Dessa forma, o objetivo deste trabalho é apresentar, por meio de uma revisão de literatura, o papel do 10MDP no processo de adesão em restaurações dentárias.

REAOdonto | Vol. 3 | e5759 | DOI: https://doi.org/10.25248/REAOdonto.e5759.2021 Página 2 de 6 


\section{REVISÃO BIBLIOGRÁFICA}

\section{História da adesão}

O grande avanço da Odontologia Restauradora se deve a técnica do condicionamento ácido, descrito por Buonocore, em 1955, que observou uma melhor aderência das tintas em superfícies metálicas através da utilização do ácido fosfórico e, assim, implementou na Odontologia, de maneira análoga, o condicionamento ácido em esmalte dando origem a Era Adesiva. Previamente a Buonocore, em 1951, foram realizadas tentativas, pelo químico suíço Hagger, de promover adesão da resina acrílica ao órgão dental através do monômero funcional glicerofosfato dimetacrilato (GPDM). Pesquisas feitas em 1952, lideradas por Kramer e McLean, relataram que o monômero GPDM potencializou a adesão à dentina, criando uma camada intermediária, através da infiltração do monômero à superfície dentinária (CARVALHO EC, et al., 2019; MEERBEEK BV, et al., 2020)

Essa camada intermediária foi descrita por Nakabayashi N, et al. (1982), denominando-a camada híbrida, cuja formação é dada pela desmineralização da dentina, seguida pela penetração dos monômeros resinosos por toda a extensão da rede de fibras colágenas, e finalizada com a polimerização do adesivo. Essa interface é considerada como a camada ideal para o processo de adesão (MEERBEEK BV, et al., 2020)

Nos últimos anos, devido a complexidade da Odontologia Restauradora, os sistemas adesivos estão em constante evolução com o objetivo de reduzir os passos clínicos para sua aplicabilidade e minimizar os problemas decorrentes das falhas no processo de adesão como as microinfiltrações, cárie secundária e sensibilidade pós-operatória. Nesse âmbito, foram introduzidos no mercado odontológico novos sistemas adesivos, sendo eles: sistemas adesivos autocondicionantes de dois passos (primer acídico e adesivo em frascos separados) e um passo (primer acídico e adesivo em frasco único) e sistemas universais denominados como "all-in-one" que se diferem dos demais por poderem apresentar em sua composição um importante agente de união, o silano, e, ainda, pela opção do condicionamento ácido, sendo este passo de autonomia do próprio cirurgião-dentista (CARVALHO EC, et al., 2019; CARRILHO E, et al., 2019; ARINELLI AMD, et al., 2016; DE MELO L, et al., 2019).

\section{Adesão química}

Devido à composição química do esmalte, o qual apresenta um conteúdo mais homogêneo sendo composto por $96 \%$ de material inorgânico (cristais de hidroxiapatita) e $4 \%$ conteúdo orgânico (proteínas e lipídios) e água, a adesão nesse substrato é considerada mais estável e de fácil desempenho. Entretanto, 0 mesmo não ocorre na dentina, pois sua composição dispõe de alto teor orgânico, representado, predominantemente, pelas fibras colágenas. Além disso, Nakabayashi N, et al. (1982), trouxe o conceito de que a dentina é um tecido úmido constituído por uma rede tubular com prolongamentos odontoblásticos por toda sua extensão, que se comunicam a polpa e tornam a superfície dentinária hidrofílica. Dessa forma, a soma de tais fatores configura a adesão em dentina um processo mais complexo e desafiador para as restaurações dentárias (CARDOSO MV, et al., 2011; TERUEL JD, et al., 2015).

Nessa perspectiva, para que a adesão na dentina seja eficaz, é necessário a formação de tags, ou seja, retenção de resina dentro dos túbulos dentinários para que se obtenha estabilidade da adesão. Contudo, a obtenção dos tags resinosos pode ser prejudicada por fatores como: profundidade e umidade da dentina; acidez causada pela técnica do condicionamento ácido; colabamento das fibras colágenas. A impossibilidade da penetração adequada do adesivo pode acarretar na degradação hidrolítica por ação das enzimas metaloproteinases do material orgânico que não foi infiltrado pelos monômeros resinosos (CARVALHO EC, et al., 2019; CARRILHO E, et al., 2019; TURP V, et al., 2013; TJÄDERHANE L, et al., 2013).

Portanto, é necessário que as fibras colágenas e os túbulos dentinários sejam totalmente infiltrados para a obtenção de uma camada híbrida estável, que é o objetivo principal do processo da adesão. Nesse contexto, as ligações químicas provenientes dos monômeros funcionais que compõem os sistemas adesivos possuem a capacidade de melhorar a aderência entre o material sintético e o substrato orgânico, 
conferindo forças adesivas maiores quando comparadas à adesão mecânica. Logo, a presença desses monômeros funcionais nos sistemas adesivos intensifica a adesão química e, dessa forma, favorece a estabilidade e durabilidade das restaurações dentárias (CARVALHO EC, et al., 2019; CARRILHO E, et al., 2019; TURP V, et al., 2013, WANG X, et al., 2013; BRESCHI L, et al., 2010; RUSSO DS, et al., 2019).

\section{Papel do 10-MDP}

A incorporação de monômeros funcionais em sistemas adesivos promove a interação química entre substrato orgânico e material resinoso, o que resulta em maiores forças adesivas quando comparadas à adesão micromecânica. Dentre os monômeros funcionais, se destaca o 10-MDP devido à sua capacidade de estabelecer ligações químicas em virtude da sua estrutura molecular que permite um comportamento polar favorável à adesão, e, ainda, auxilia na proteção das fibras de colágeno através da formação de sais de MDP-cálcio (CARRILHO E, et al., 2019; WANG X, et al., 2013; RUSSO DS, et al., 2019).

O monômero 10-MDP atua como um agente de ligação entre compósitos resinosos, óxidos metálicos e substratos dentários. Sendo assim, o 10-MDP possui a capacidade de promover uma melhor adesão quando comparado aos outros monômeros funcionais. Isso ocorre em virtude do seu potencial de formar uma camada híbrida estável através das ligações iônicas com os cristais de hidroxiapatita. Esta estabilidade se dá devido à sua estrutura química formada por uma extensa cadeia hidrofóbica espaçadora de carbonos que liga o grupo fosfato que apresenta alta afinidade pelo cálcio (presente em esmalte e dentina) ao grupo metacrilato polimerizável, e assim, promove fortes ligações entre substrato dental e material resinoso. Somado a isso, por ser um monômero mais hidrofóbico, o 10-MDP apresenta menor absorção de água, fato que reduz a degradação hidrolítica da interface resina/dentina e, consequentemente, aumenta a durabilidade da restauração dentária. Por estes motivos, o 10-MDP é considerado como padrão ouro no processo de adesão (CARRILHO E, et al., 2019; FEITOSA VP, et al., 2014; RUSSO DS, et al., 2019; LLERENA-ICOCHEA AE, et al., 2017; HOSHIKA S, et al., 2017).

Contudo, como o monômero 10-MDP interage com cristais de hidroxiapatita, a técnica de condicionamento com ácido fosfórico desmineraliza a superfície dentária de forma que não permaneça cristais suficientes para que o monômero faça ligações efetivas. Portanto, em esmalte que teve a superfície condicionada, o monômero 10-MDP não apresenta uma adesão significativa, devido a quantidade reduzida de cálcio disposta no substrato dental, fator que diminui as interações químicas neste tecido dentário. Ademais, apesar do monômero 10-MDP possuir uma maior resistência de união, este monômero funcional não estabelece uma aderência adequada quando aplicado em dentinas profundas, pois para formação da camada híbrida é necessário a presença da dentina intertubular e peritubular. Logo, a medida que a profundidade da dentina aumenta, as forças das interações químicas são reduzidas, pois quando há uma maior quantidade de túbulos dentinários por área, o conteúdo mineralizado diminui (MEERBEEK BV, et al., 2020; TURP V, et al., 2013).

\section{0-MDP e adesivos universais}

A literatura apresenta como os fabricantes buscam diminuir as etapas clínicas com o objetivo de tornar o processo restaurador mais ágil, facilitar para o clínico e diminuir as chances de erros, tendo hoje no mercado os adesivos universais (CARVALHO EC, et al., 2019; CARRILHO E, et al., 2019; ARINELLI AMD, et al., 2016).

Nos frascos de adesivos universais, pode-se encontrar o silano na formulação, ou seja, no mesmo frasco que outros monômeros, como o 10-MDP. Portanto, assumindo a maior acidez encontrada no frasco destes adesivos como consequência das moléculas de MDP, o pH ideal para o silano é alterado, causando uma reação de autocondensação. Com isso, durante procedimentos de cimentação, a literatura indica o tratamento prévio da peça com silano puro ao utilizar adesivos universais com 10-MDP (DE MELO L, et al., 2019).

Muitos autores são unânimes em ressaltar a ideia de que há diferenciais de adesão entre sistemas adesivos comerciais dependendo do substrato dental e de outros componentes incluídos nas formulações de adesivos. Monômeros funcionais não são os únicos componentes nas formulações, portanto, o protocolo 
clínico para aplicação de adesivos autocondicionantes não pode ser o mesmo para todos os sistemas comerciais. Além de que alguns adesivos universais produzem interfaces adesivas ruins por serem menos concentrados em 10-MDP, o que sugere que uma concentração e pureza ótimas de 10-MDP em adesivos autocondicionantes e universais podem existir para que o potencial máximo desse monômero funcional seja alcançado (CARRILHO E, et al., 2019; YAGUCHI T, et al., 2017; FUJITA-NAKAJIMA K, et al., 2018).

Carrilho E, et al. (2019) e Feitosa VP, et al. (2014) afirmam que o 10-MDP foi identificado como sendo capaz de estabelecer uma interação química muito intensa e estável com a hidroxiapatita. A ligação produzida por adesivos contendo 10-MDP parece ser muito estável, como confirmado pela baixa taxa de dissolução de seus sais de cálcio na água, tais sais do MDP-Ca contribuem para a proteção das fibras de colágeno.

Outro fator que Kim EC, et al. (2015) e Putzeys E, et al. (2018) destacam é que, ao usar sistemas adesivos autocondicionantes fortes, a solução adesiva pode penetrar nos túbulos dentinários e atingir a polpa, principalmente ao restaurar cavidades profundas. Atualmente, a literatura carece de estudos que compreendam o efeito citotóxico desses materiais sobre a polpa, pois é difícil imitar as condições clínicas de sua aplicação. Alguns estudos relataram que concentrações minimamente tóxicas de 10-MDP promoveram uma resposta inflamatória e suprimiram a diferenciação odontoblástica das células da polpa dentária.

\section{Adesão em zircônia}

Em relação ao processo de cimentação de peças cerâmicas não graváveis, o monômero funcional 10MDP também apresenta um papel diferenciado. Apesar das diversas vantagens que a zircônia trouxe para a Odontologia restaurativa, a adesão deste tipo de cerâmica, mesmo com os avanços tecnológicos, ainda se constitui como um grande desafio. A zircônia é considerada um material ácido resistente, ou seja, não pode ser condicionada pelo ácido fluorídrico por conta da sua estrutura ser constituída pela porção cristalina e não matriz vítrea. Portanto, um método alternativo é imprescindível para melhorar a ligação resina-zircônia (AKAY C, et al., 2017; ZARANDI PK, et al, 2020).

Desta forma, para que a adesão à zircônia seja efetiva é necessário desenvolver uma interação química entre a superfície e o cimento resinoso aplicado, pois possuem resistência maior que as adesões mecânicas, e o monômero 10-MDP atua justamente como agente ligante entre compósitos resinosos e óxidos metálicos. Nesse sentido, o uso de primers e cimentos resinosos que contêm 10-MDP em sua composição, como o cimento resinoso Panavia F 2.0 Half, possuem o potencial de promover uma adesão de tenacidade e estabilidade maior. Segundo Akay C, et al. (2017), a utilização de cimentos resinosos que contêm monômeros 10-MDP associados à tratamentos de superfície constitui o método que apresenta maior eficácia no quesito de adesão das restaurações em zircônia (Quadro 1) (CARRILHO E, et al., 2019; TURP V, et al., 2013; LLERENA-ICOCHEA AE, et al., 2017; AKAY C, et al., 2017).

Quadro 1 - Exemplos de materiais Odontológicos que apresentam 10-MDP na sua composição.

\begin{tabular}{|c|c|c|}
\hline Material & Função & Marca comercial \\
\hline Clearfil SE Bond & Adesivo autocondicionante & Kuraray \\
\hline Clearfil Ceramic Primer & Primer Cerâmico & Kuraray \\
\hline Single Bond Universal & Adesivo Universal & $3 \mathrm{M}-\mathrm{ESPE}$ \\
\hline All-Bond Universal & Adesivo Universal & Bisco \\
\hline RelyX Ultimate & Cimento Resinoso & $3 \mathrm{M}-\mathrm{ESPE}$ \\
\hline Panavia F 2.0 Half & Cimento Resinoso & Kuraray \\
\hline Ambar & Adesivo convencional & FGM \\
\hline Alloy Primer & Primer para metal & Kuraray \\
\hline
\end{tabular}

Fonte: Lima AS, et al., 2020.

\section{CONSIDERAÇÕES FINAIS}

Diante do exposto, nota-se que o monômero 10-MDP se destaca por apresentar ligação tanto a hidroxiapatita dos tecidos dentais quanto aos compósitos e cimentos resinosos promovendo assim uma 
resistência de união mais estável e duradoura, sendo, por tal motivo, considerado como um monômero padrão ouro para a adesão em dentina. Ao passo que, a adesão em esmalte ocorre majoritariamente por embricamento mecânico, não apresentando relação significativa com a presença do monômero 10-MDP. Na dentina, a adesão apresenta resultados superiores quando a superfície é preparada com sistemas adesivos autocondicionantes e universais contendo 10-MDP. Entretanto, esses monômero não consegue uma união adequada em cavidades profundas devido à dificuldade de formação de uma camada híbrida eficaz em tais condições. No que concerne às cerâmicas de zircônia, fica clara a importância do monômero 10-MDP, atuando como agente ligante e melhorando suas propriedades de resistência. Por fim, o presente estudo buscou relatar com clareza as propriedades desse monômero e suas principais funções dentro das restaurações diretas com resina composta e também suas aplicabilidades em restaurações indiretas com cerâmicas odontológicas. Com isso, a atuação do monômero $10 \mathrm{MDP}$ durante todos esses anos de estudos, trouxe consigo inovações e uma nova visão para reabilitação oral dos pacientes, conferindo assim, principalmente, o sucesso da adesão aos tecidos dentários e a longevidade dos tratamentos odontológicos.

\section{REFERÊNCIAS}

1. AKAY C, et al. Effects of Hot Chemical Etching and 10-Metacryloxydecyl Dihydrogen Phosphate (MDP) Monomer on the Bond Strength of Zirconia Ceramics to Resin-Based Cements. J Prosthodont. 2017; 26(5): 419-423.

2. ARINELLI AMD, et al. Sistemas adesivos atuais. Rev Bras Odontol. 2016; 73(3): 242.

3. BRESCHI L, et al. Use of a specific MMP-inhibitor (galardin) for preservation of hybrid layer. Dent Mater. 2010; 26(6):571-578.

4. CARDOSO MV, et al. Current aspects on bonding effectiveness and stability in adhesive dentistry. Aust. Dent. $2011 ; 56: 31-44$.

5. CARRILHO E, et al. 10-MDP Based Dental Adhesives: Adhesive Interface Characterization and Adhesive Stability A Systematic Review. Materials (Basel). 2019; 12 (5):790

6. CARVALHO EC, et al. Análise de interfaces de sistemas restauradores diretos em esmalte e em dentina humana. Matéria (Rio J.). 2019; 24(3): e12391.

7. DE MELO LA, et al. Efficacy of prostheses bonding using silane incorporated to universal adhesives or applied separately: A systematic review. J Indian Prosthodont Soc. 2019; 19(1): 3.

8. FEITOSA VP, et al. The role of spacer carbon chain in acidic functional monomers on the physicochemical properties of self-etch dental adhesives. J Dent. 2014; 42(5): 565-574.

9. FUJITA-NAKAJIMA K, et al. NMR study on the demineralization mechanism of the enamel and dentin surfaces in MDP-based all-in-one adhesive. Dent. Mater. J. 2018; 37 (4): 693-701.

10. HOSHIKA S, et al. GPDM- and 10-MDP-based Self-etch Adhesives Bonded to Bur-cut and Uncut Enamel "Immediate" and "Aged" $\mu$ TBS. J Adhes Dent. 2018; 20(2): 113-120.

11. KIM EC, et al. Effect of the Acidic Dental Resin Monomer 10-methacryloyloxydecyl Dihydrogen Phosphate on Odontoblastic Differentiation of Human Dental Pulp Cells. Basic Clin Pharmacol Toxicol. 2015; 117(5): $340-349$.

12. LLERENA-ICOCHEA AE, et al. Bonding Polycrystalline Zirconia With 10-MDP-containing Adhesives. Oper. Dent. 2017; 42(3): 335-341.

13. MEERBEEK BV, et al. From Buonocore's Pioneering Acid-Etch Technique to Self-Adhering Restoratives. A Status Perspective of Rapidly Advancing Dental Adhesive Technology. J Adhes Dent. 2020; 22 (1): 7-34.

14. NAKABAYASHI N, et al. The promotion of adhesion by the infiltration of monomers into tooth substrates. Journal of biomedical materials research. 1982; 16(3): 265-273.

15. PUTZEYS E, et al. In-vitro transdentinal diffusion of monomers from adhesives. J Dent. 2018; 75:91-97.

16. RUSSO DS, et al. Adhesion to Zirconia: A Systematic Review of Current Conditioning Methods and Bonding Materials. Dent J. 2019; 7(3): 74.

17. TERUEL JD, et al. Comparison of Chemical Composition of Enamel and Dentine in Human, Bovine, Porcine and Ovine Teeth. Arch Oral Biol. 2015; 60(5): 768-75.

18. TJÄDERHANE L, et al. Optimizing dentin bond durability: control of collagen degradation by matrix metalloproteinases and cysteine cathepsins. Dent Mater. 2013; 29(1):116-135.

19. TURP V, et al. Adhesion of 10-MDP containing resin cements to dentin with and without the etch-and-rinse technique. J Adv Prosthodont. 2013; 5(3): 226-233.

20. WANG X, et al. Influence of priming time and primer's concentrations on bovine enamel bond strengths. J Adhes Sci Technol. 2013; 27(23): 2558-2570.

21. YAGUCHI T. Layering mechanism of MDP-Ca salt produced in demineralization of enamel and dentin apatite. Dent Mater. 2017; 33 (1): 23-32.

22. YOSHIHARA K, et al. Functional monomer impurity affects adhesive performance. Dent Mater. $2015 ; 31$ (12): 1493-501.

23. ZARANDI PK, et al. The Effect of Sandblasting and Coating of Zirconia by Nano Composites on Bond Strength of Zirconia to Resin Cements. J Dent. (Shiraz) 2020; 21(1): 63-68. 